\title{
ESTUDO DOS PACIENTES PEDIATRICOS ATENDIDOS EM PRONTO- SOCORRO OFTALMOLOGICO ASSOCIADO AOS DIAGNOSTICOS ENCONTRADOS
}

\section{Pôster}

Autores deste trabalho:

Carolina Gaspar Carvalho Heil Silva: Complexo Hospitalar Padre Bento de Guarulhos (CHPBG)

Área do Trabalho: Pediatria

Número de inscrição: 136723

Data da submissão:31/08/2016 às 23:11

\section{Justificativa}

O atendimento pediátrico em pronto-socorro oftalmológico é parte importante da demanda, mas a literatura é escassa sobre o perfil atendido e os diagnósticos encontrados. Os dados disponíveis mostram que condições que não causam danos à visão são parcela relevante dos atendimentos. Razões podem incluir a pouca prática com doenças oculares e o conhecimento insuficiente adquirido na faculdade apontados por plantonistas. $\mathrm{O}$ estudo justifica-se ao revelar dados deste tipo de perfil associados aos diagnósticos encontrados.

\section{Objetivo(s)}

Avaliar o perfil epidemiológico pediátrico no pronto-socorro de Oftalmologia do CHPBG e conhecer as causas de encaminhamento ao setor.

\section{Método(s)}

Estudo transversal, descritivo, não intervencionista baseado em informações coletadas através de ficha padrão dos pacientes de 0 a 18 anos incompletos atendidos em março e abril de 2016. As informações foram obtidas mediante assinatura de Termo de Consentimento Livre e Esclarecido pelos responsáveis e Termo de Assentimento pelos pacientes de 12 a 18 anos incompletos. O estudo foi aprovado pelo Comitê de Ética em Pesquisa do próprio hospital.

\section{Resultado(s)}

Foram pesquisados 194 pacientes: 108 meninos (55\%) e 86 meninas (45\%), com média de idade de 11 anos. A faixa etária predominante foi 12 a 18 anos incompletos (38\%) e a 
menos frequente, 4 a 6 anos (10\%). A patologia mais diagnosticada foi conjuntivite (54\%), alérgica e infecciosa, seguida do conjunto blefarite/hordéolo/calázio (18\%). O tempo de queixa prevalente foi 2 a 7 dias (54\%), mas histórias com mais de uma semana também foram significativas (24\%). Dos acompanhantes, $79 \%$ eram as próprias mães, e, de todos eles, $47 \%$ possuía, no mínimo, o ensino médio completo.

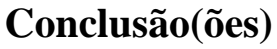

A comparação dos dados encontrados foi dificultada pela escassez de dados similares na literatura, sendo necessários mais estudos semelhantes para este fim. Apesar disso, encontrou-se que patologias que poderiam ser resolvidas em serviços de menor complexidade foram frequentes no setor, o que é compatível com os poucos dados disponíveis, considerando-se a alta escolaridade encontrada e a unidade ser referenciada. Difusão dos conhecimentos oftalmológicos aos plantonistas e campanhas educacionais à população podem ser oportunas, visando a melhoria do atendimento à população pediátrica nas emergências. 